\title{
Correlation of Ultrasound Thyroid Imaging Reporting and Data System with Histopathology findings among patients in Uganda
}

Hamdi Mohamed Isse ( $\sim$ drhamdisom@gmail.com )

Makerere University

Robert Lukande

Makerere University

Senai Goitom Sereke

Makerere University

Fualal Jane Odubu

Makerere University

Rita Nassanga

Makerere University

Samuel Bugeza

Makerere University

\section{Case Report}

Keywords: ACR, TI-RADS, ultrasound, cytology, correlation

Posted Date: January 6th, 2023

DOI: https://doi.org/10.21203/rs.3.rs-1261509/v2

License: (9) (i) This work is licensed under a Creative Commons Attribution 4.0 International License.

Read Full License 


\section{Abstract}

Background: Ultrasonography (US) is a noninvasive modality for the initial assessment of thyroid nodules. Thyroid Imaging Reporting and Data System (TI-RADS) has demonstrated good performance in differentiating malignant thyroid nodules. However, the correlation of ACR TI-RADS with FNNA cytology is unusual in our setting. The study aims at correlating TI-RADS with cytology among patients referred for US-guided fine-needle none aspiration (FNNA) cytology at Mulago National Referral Hospital (MNRH).

Methods: This was a hospital-based cross-sectional study that recruited 132 patients with thyroid nodules. Spearman's correlation was used to establish a relationship between TI-RADS and FNNA cytology findings. The diagnostic accuracy of TI-RADS was assessed using sensitivity, specificity, positive and negative predictive values, positive and negative likelihood ratios.

Results: Of 132 study participants $90 \%(n=117)$ were females and the mean age of $41 \pm 13$. One hundred sixty-one thyroid nodules were analyzed. More than half of the thyroid nodules $(54.7 \%, n=87)$ were solid or almost solid, $96.9 \%(n=154)$ were shaped wider than tall, with $57.2 \%(n=91)$ having smooth margins while $83.7 \%(n=133)$ were hyperechoic or isoechoic and $88.7 \%(n=141)$ had none or large comet-tail artifact. TR3 was the commonest at $42.9 \%(n=69)$. The proportion of malignancy for TR4 and TR5 were 73.3\% and $85.7 \%$ respectively. The correlation between ACR TI-RADS and the Bethesda system of thyroid classification scores was $r=0.577$. The sensitivity, specificity, PPV, NPV, positive and negative likelihood ratios of ACR TI-RADS were $90.9 \%, 98.5 \%, 90 \%, 99.3 \%, 62.3$, and 0.1 respectively.

Conclusion: We found that ACR TI-RADS classification is an appropriate and non-invasive method for assessing thyroid nodules in routine practice. It can safely reduce the number of unnecessary FNNA in a significant proportion of benign thyroid lesions. Thyroid nodules classified as TR3 should be followed routinely. ACR TI-RADS should be standardized as the screening tool in resource-limited areas.

\section{Background}

Thyroid nodule (TN) is a common thyroid disorder with global prevalence ranging; $4-7 \%$ by palpation, $19-68 \%$ by ultrasound, and $8-65 \%$ by pathologic examination at autopsy $(1,2)$. This increase is thought to be related to early detection by high-resolution ultrasound and the discovery of subclinical TNs $(3,4)$. TN can be classified as either benign or malignant. Most of the TN are benign and less than $5-10 \%$ are malignant (4). In Africa, the prevalence of benign TN is at $89 \%$ while that of malignant TN stands at $11 \%$, showing some variation from the expected global benign and malignant TN percentages (5). This could be due to the high prevalence of iodine deficiency goiter (6). In Uganda, nodular thyroid disease is more common than diffuse thyroid disease accounting for $82 \%$ of all the patients referred with thyroid symptoms (7). Furthermore, a study done at MNRH found that $5 \%$ of the TN evaluated were malignant, $18 \%$ suspicious, and $75 \%$ benign (8). Hence the need to identify suitable tools to assess the risk of malignancy in patients with a TN is crucial (9). 
The differentiation of malignant and benign TN is of utmost importance in clinical evaluation since treatment is different for each type of nodule (10). Ultrasound can be used to differentiate benign from malignant nodules based on certain characteristics (10). To improve the diagnostic sensitivity and specificity of the ultrasound evaluation of TNs, the Thyroid Imaging Reporting and Data System (TIRADS) was proposed (11). The American College of Radiology Thyroid Imaging Reporting and Data Systems (ACR TI-RADS) is a 5-point classification system developed to determine the risk of cancer in TN based on ultrasound characteristics. This system has been mainly used for TN that are $\geq 1 \mathrm{~cm}$. This system evaluates ultrasound features in five categories: composition, echogenicity, shape, margin, and echogenic foci; the nodule's total points determine its risk level, which ranges from TI-RADS 1 (TR1) (benign) to TI-RADS 5 (TR5) (highly suspicious) (12). None of these ultrasound features can be used in isolation to accurately differentiate benign from malignant TNs. Fine-needle none aspiration (FNNA) biopsy is the next, critical step in the workup of a TN after ultrasound identifies features that warrant biopsy (13). The Bethesda System for Reporting Thyroid Cytopathology (TBSRTC) was developed to standardize thyroid cytology diagnoses to convey the biopsy findings according to a classification system that provides clear management guidelines and the associated risk of malignancy (11). ACR TIRADS is relatively new (14) and has not been widely adopted for use in Uganda. Furthermore, the correlation of ACR TI-RADS with FNNA cytology is unusual in our setting.

Age and sex correlate with the pathogenesis and increased prevalence of $\operatorname{TN}(15,16)$. The incidence of nodules has been reported to be four times higher in women as opposed to men (17). This could be a result of hormonal influences of both estrogen and progesterone (18). Smoking, radiation exposure, pregnancy, multiparity, and abnormal BMI ranges have also been identified as predisposing factors (19). Genetic factors, environmental influences, lifestyle, and access to medical care could be associated with variation in thyroid cancer incidence by geographic area and ethnicity (20). TNs are uncommonly cited in third world countries where the disease is attributed to iodine deficiency disorders due to low salt consumption (21). The study, therefore, sought to investigate the correlation of TI-RADS with cytology among patients referred for the US-guided FNNA cytology of thyroid nodule at MNRH.

\section{Methods}

\section{Study design and setting}

This was a hospital-based descriptive cross-sectional study conducted at the ultrasound unit of the department of radiology and department of pathology of MNRH, Kampala, Uganda between November 2020 and March 2021. The radiology department provides wide imaging services including the US, computed tomography, plain radiography, and interventional radiology. It has eleven radiographers, five consultant radiologists, and four nurses. The department of pathology is situated at the school of biomedical science and serves the roles of teaching, research, as well as offering diagnostic histo/cytopathology and autopsy services. The majority of the patients referred for the US-guided FNNA cytology are from the endocrine-surgical outpatient clinic at MNRH. The clinic runs every Wednesday from 8:00 AM to 2:00 PM and receives approximately 15-17 patients weekly. 


\section{Study population}

All consenting participants with thyroid nodule $/ \mathrm{s} \geq 1 \mathrm{~cm}$ in B-mode ultrasound scan were scheduled for US-guided FNNA cytology. All participants were at the age of 18 and above during the study period. Participants with prolonged bleeding time, extensively calcified nodules, had emphysema, and had clinical and laboratory features of thyrotoxicosis were excluded from the study.

\section{Sample size}

The sample size was determined using Kish Leslie's formula and the final adjusted sample size was 132 participants

\section{Study procedure}

All patients referred from the endocrine-surgical outpatient clinic with TN in B-mode ultrasound scan scheduled for US-guided FNNA cytology during the study period were screened for nodules using ultrasound. Those with $\mathrm{TN} \geq 1 \mathrm{~cm}$ in Bmode ultrasound and who have consented were recruited into the study. Under the supervision of a radiologist, US evaluation was performed on an SIUI Apogee 5300 Ultrasound machine labeled MHC-DDT-US-0012 with high-frequency linear probes of 7.5MHz. For obese patients or big thyroid lesions, a $5 \mathrm{MHz}$ transducer was used for greater penetration. The US was done with the patient in supine position and neck hyper-extended, and the entire gland was examined. Hyperextension of the neck was obtained by placing a pillow under the shoulders. The neck was scanned in sagittal, transverse, and oblique sections to optimally visualize both lobes of the thyroid and isthmus. Color Doppler imaging was utilized. Imaging of the lower poles of the thyroid was obtained by making the patient swallow as this tends to raise the thyroid gland in the neck.

TN sonographic characteristics like composition, shape, echogenicity, margins and echogenic foci were recorded and points were assigned to each nodule for the separate categories according to ACR TI-RADS guidelines (11). The sum of the points in each category determined the TI-RADS level assigned to each nodule, with TR1 indicating 0 points; TR2-2 points; TR3-3 points; TR4-4-6 points; and TR5-7 or more points (Fig. 1). The final sonographic diagnosis was reached with the help of a consultant radiologist. The data obtained from the ACR point table was used to correlate with cytology results. A 23-gauge needle with a clear hub was used to obtain a sample from the nodules for each TI-RADS category and a maximum of two nodules was sampled in a patient. The sample was gently expelled onto the surface of a labeled microscope slide from the needle tip by using clear syringe $(5-10 \mathrm{mls})$. A smearing slide was then slid over the specimen ensuring that both slides are smeared. One slide underwent wet-fixation with alcohol and this was stained using the Papanicolaou method while the other slide was air-dried at room temperature and this was stained with the Diff quick method. After this, an experienced pathologist evaluated all samples according to the Bethesda system.

The categories and their risk of malignancy were recorded as; 


\begin{tabular}{|ll|}
\hline I & Non-diagnostic \\
\hline II & Benign \\
\hline III & $\begin{array}{l}\text { Atypia of undetermined significance (AUS)/follicular lesion of undetermined significance } \\
\text { (FLUS), }\end{array}$ \\
\hline IV & Follicular neoplasm (FN)/suspicious for follicular neoplasm (SFN) \\
\hline V & Suspicious for malignancy (SM) \\
\hline VI & Malignant \\
\hline
\end{tabular}

The ACR TI-RADS level, which ranges from TR1 (benign) to TR5 (high suspicion of malignancy) was also used to categorize the nodules. Coded US images were stored and printed.

\section{Statistical analysis}

The data was entered into epi-data version 3.1 then exported into Stata statistical software version 14 for analysis. To describe patient characteristics, categorical variables were summarized using frequencies and percentages while continuous variables used mean and standard deviation. While 132 patients were enrolled in the study, 2 nodules per participant were included in the study resulting in an analytic sample size of 161. Pairwise analysis was not done to control for clustering because the patient identifiers were replaced with study numbers for the study purpose. The ACR TI-RADS classification criteria were used to classify nodules as TR1-5 and then presented as frequencies and percentages. The difference in the proportions of the ACR TI-RADS sonographic criteria was tested using Fischer Exact test. Spearman's correlation coefficient was used to establish the correlation between ACR-TI-RADS and FNNA cytology findings.

To determine the diagnostic effectiveness of TI-RADS in characterizing thyroid nodules and predicting cytological findings; sensitivity, specificity, positive and negative predictive values, positive and negative likelihood ratios with corresponding $95 \%$ confidence levels were calculated using the Bethesda system of thyroid classification as a gold standard. ACR TI-RADS was dichotomized by considering TR4, 5 as a positive screen for malignancy and TR1 to 3 as screen negative. Bethesda was also dichotomized by classifying 4 to 6 as malignancy and $1-3$ as no malignancy.

\section{Results}

Of the 132 study participants, the majority were females $(90 \%, n=117)$ with a mean age of $41 \pm 13$. Twenty-nine (22\%) had 2 or more nodules but only two nodules were biopsied giving a total of 161 . Of these, 2 nodules of 2 patients were inadequate and were excluded from the final analysis. Most of the participants were from the central region of Uganda, 74 (56.9\%). (Table 1) 
Table 1

Sociodemographic characteristics of patients who underwent ultrasound-guided FNNA in MNRH.

\begin{tabular}{|lll|}
\hline Variables & Frequency $n=130$ & Percentage \\
\hline Gender & & \\
Male & 13 & 10.0 \\
\hline Female & 117 & 90.0 \\
\hline Age in years & & \\
Mean \pm SD & $41 \pm 13.0$ & \\
Regions in Uganda & \\
\hline Central & 74 & 56.9 \\
\hline Eastern & 19 & 14.6 \\
\hline Western & 21 & 16.2 \\
\hline Northern & 16 & 12.3 \\
\hline SD = standard deviation & \\
\hline
\end{tabular}

More than half of the nodules $87(54.7 \%)$ had a composition that was mostly solid or almost solid and $154(96.9 \%)$ were shaped wider than tall. One hundred thirty-three $(83.7 \%)$ of the nodules were hyperechoic/isoechoic, 60 (37.7\%) had ill-defined margins and 141 (88.7\%) had none or large comet tail artifact (Table 2). The majority of the nodules 69 (42.9\%) were classified as TR3 followed by TR2 56 (34.8\%), 14 (8.7\%) were classified as TR1 and 7 (4.3\%) were classified as TR5. Furthermore, TR3 was the most frequently observed categorization in both males (42.9\%) and females (44.1\%) (Fig. 2). 
Table 2

Sonographic appearance of thyroid nodules based on ACR TI-RADS

\begin{tabular}{|c|c|c|}
\hline ACR-TIRADS based on & Frequency $n=159$ & Percentage \\
\hline \multicolumn{3}{|l|}{ Composition } \\
\hline cystic/almost completely cystic & 10 & 6.3 \\
\hline Spongiform & 3 & 1.9 \\
\hline mixed cystic and solid & 59 & 37.1 \\
\hline solid/ almost solid & 87 & 54.7 \\
\hline \multicolumn{3}{|l|}{ Shape } \\
\hline wider than tall & 154 & 96.9 \\
\hline taller than wide & 5 & 3.1 \\
\hline \multicolumn{3}{|l|}{ Echogenicity } \\
\hline anechoic & 13 & 8.2 \\
\hline hyperechoic or isoechoic & 133 & 83.7 \\
\hline hypoechoic & 12 & 7.6 \\
\hline very hypoechoic & 1 & 0.6 \\
\hline \multicolumn{3}{|l|}{ Margin } \\
\hline smooth & 91 & 57.2 \\
\hline ill defined & 60 & 37.7 \\
\hline Lobulated/ irregular & 4 & 2.5 \\
\hline extra thyroid extension & 4 & 2.5 \\
\hline \multicolumn{3}{|l|}{ Echogenic foci } \\
\hline none/ large comet tail artifact & 141 & 88.7 \\
\hline macro calcification & 12 & 7.6 \\
\hline peripheral calcifications & 1 & 0.6 \\
\hline punctate echogenic foci & 5 & 3.1 \\
\hline
\end{tabular}

Two (1.2\%) of the nodules classified as Bethesda 1 and 141 (85.5\%) classified as Bethesda II were considered benign, and 18 (11.2\%) nodules classified as Bethesda 4-6 were considered malignant. Six nodules (3.7\%) that were categorized as TR5 truly turned out to be malignant as per Bethesda classification (Bethesda 6). Similarly, most of the nodules categorized as TR4 turned out to be suspicious 
for malignancy as per the Bethesda classification (Bethesda 5). One out of the 141 nodules was Riedel's thyroiditis (Bethesda 2) while categorized as TR5 on ultrasound. Moreover, one (1) out of the 69 nodules categorized as TR3 was classified as suspicious for follicular neoplasm (Bethesda classification 4). On comparing TI-RADS classification with the Bethesda system of classification, the proportion of malignancy for TR1, 2, 3, 4, and 5 was $0,0,1.4,73.3$, and $85.7 \%$, respectively. The risk of malignancy was determined by dividing total Bethesda scores from $4-6$ by the total TI-RADS level (Table 3 ). There was a moderate correlation between ACR TI-RADS and the Bethesda system of thyroid classification scores ( $r=$ $0.577)$ and this correlation was statistically significant $(p<0.001)$.

Table 3

Correlation of ACR-TIRADS and Bethesda system of thyroid classification

\begin{tabular}{|lllllllll|}
\hline \multicolumn{7}{c|}{ BETHESDA system of thyroid classification } & & \\
\hline $\begin{array}{l}\text { ACR-TIRADS } \\
\text { categorization }\end{array}$ & 1 & 2 & 3 & 4 & 5 & 6 & $\begin{array}{l}\text { Total } \\
\text { n (\%) }\end{array}$ & $\begin{array}{l}\text { Proportion } \\
\text { of } \\
\text { malignancy } \\
(\%)\end{array}$ \\
\hline TIRADS 1 & 1 & 13 & 0 & 0 & 0 & 0 & $\begin{array}{l}14 \\
(8.7)\end{array}$ & 0 \\
\hline TIRADS 2 & 1 & 55 & 0 & 0 & 0 & 0 & $\begin{array}{l}56 \\
(34.8)\end{array}$ & 0 \\
\hline TIRADS 3 & 0 & 68 & 0 & 1 & 0 & 0 & $\begin{array}{l}69 \\
(42.9)\end{array}$ & 1.4 \\
\hline TIRADS 4 & 0 & 4 & 0 & 2 & 8 & 1 & $\begin{array}{l}15 \\
(9.3)\end{array}$ & 73.3 \\
\hline TIRADS 5 & 0 & 1 & 0 & 0 & 0 & 6 & 7 & 85.7 \\
\hline Total n (\%) & 2 & $141(85.5)$ & $0(0)$ & $3(1.8)$ & $8(4.9)$ & $7(4.3)$ & 161 & \\
\hline
\end{tabular}

The sensitivity and specificity of ACR TI-RADS to detect malignancy was $94.4 \%$ with a $95 \% \mathrm{Cl}$ of 0.944 (0.8-1.0) and $96.5 \%$ with a $95 \% \mathrm{Cl}$ of $0.965(0.9-0.99)$ respectively. The positive and negative predictive values corresponding to the above sensitivity and specificity were $77.3 \%$ and $99.3 \%$ while the positive and negative likelihood ratios were 27 and 0.06 respectively (Table 4). Hypoechoic echogenicity and solid composition combined with hypoechoic echogenicity showed the highest sensitivity to detect malignancy of $54.6 \%$ and $57.1 \%$ respectively. All the parameters used in the classification of ACR TI-RADS with exception of composition were statistically significantly associated with FNNA results, $p<0.005$. This significant association was noted for nodules that were either solid and hypoechoic or solid and hyperechoic (Table 5). 
Table 4

$2 \times 2$ ACR-TIRADS categorization of thyroid nodules and the Gold standard

\begin{tabular}{|c|c|c|c|c|}
\hline \multicolumn{5}{|c|}{ Gold Standard } \\
\hline & & Malignant & Benign & Total \\
\hline \multirow[t]{3}{*}{ ACR-TIRADS } & Positive & 17 & 5 & 22 \\
\hline & Negative & 1 & 138 & 139 \\
\hline & Total & 18 & 143 & 161 \\
\hline \multicolumn{5}{|c|}{$\begin{array}{l}\text { Sensitivity }=(17 / 18) * 100=94.4 \% \text { with } 95 \% \text { Cl of } 0.944(0.8-1.0) ; \text { Specificity }=(137 / 143) * 100=96.5 \% \\
\text { with } 95 \% \mathrm{Cl} \text { of } 0.965(0.9-1.0) \text {. PPV }=(17 / 22) * 100=77.3 \% ; \mathrm{NPV}=(138 / 139)^{*} 100=99.3 \% ; \mathrm{LR} \\
\text { Positive }=94.4 /(100-96.5)=27 ; \text { LR Negative }=(100-94.4) / 96.5=0.06\end{array}$} \\
\hline
\end{tabular}


Table 5

Distribution of sonographic features used in ACR TI-RADS categorization of thyroid nodules across the FNNA Results

\begin{tabular}{|c|c|c|c|}
\hline ACR-TIRAD and its classification parameters & Malignancy & Benign & p-value* \\
\hline & $(\%)$ & (\%) & \\
\hline \multicolumn{4}{|l|}{ Composition } \\
\hline \multicolumn{4}{|l|}{ Solid (+) } \\
\hline Non solid (-) & 21.8 & 1.4 & 0.217 \\
\hline \multicolumn{4}{|l|}{ Shape } \\
\hline \multicolumn{4}{|l|}{ Taller than wide $(+)$} \\
\hline Wider than tall $(-)$ & 10 & 0.7 & 0.001 \\
\hline \multicolumn{4}{|l|}{ Echogenicity } \\
\hline \multicolumn{4}{|l|}{ hypoechoic (+) } \\
\hline \multicolumn{4}{|l|}{ anechoic/hyper echoic/ } \\
\hline isoechoic (-) & 54.6 & 0.7 & $<0.001$ \\
\hline \multicolumn{4}{|l|}{ Margins } \\
\hline \multicolumn{4}{|l|}{ Lobulated/irregular/extra } \\
\hline \multicolumn{4}{|l|}{ thyroid extension (+) } \\
\hline Smooth/ ill defined (-) & 31.8 & 0.7 & $<0.001$ \\
\hline \multicolumn{4}{|l|}{ Echogenic foci } \\
\hline \multicolumn{4}{|l|}{ Punctate echogenic foci/ } \\
\hline \multicolumn{4}{|l|}{ peripheral calcification $(+)$} \\
\hline \multicolumn{4}{|l|}{ None or large comet tail } \\
\hline artifact/ macro calcification (-) & 27.3 & 0 & $<0.001$ \\
\hline \multicolumn{4}{|l|}{ Echogenicity \& composition combined } \\
\hline \multicolumn{4}{|l|}{ Solid\& hypoechoic nodule (+) } \\
\hline Solid \& hyperechoic nodule (-) & 57.1 & 1.5 & $<0.001$ \\
\hline
\end{tabular}

US image of TR5 nodule with its corresponding category VI Bethesda system (papillary carcinoma) is demonstrated in Fig. 3. 


\section{Discussion}

This study sought to determine the correlation of TI-RADS with TBSRTC among patients attending MNRH. We found high sensitivity and specificity of ACR TI-RADS to detect malignancy and a moderate positive correlation between ACR TI-RADS and TBSRTC. Moreover, the majority of the nodules were classified as TR3 based on sonographic appearance and the majority of the TN referred for FNNA were solid/ almost solid, wider than tall, hyperechoic or isoechoic, had a smooth margin, and had no Echogenic foci / large comet-tail artifact.

The study observed that majority of the patients were females with an average age of early forties which was consistent with other studies done in Uganda (8), India (22), and Saudi Arabia (23) that reported a similar female to male ratio and average age. This can be explained by the fact that females are more prone to symptomatic thyroid nodular disease as a result of hormonal influences of estrogen and progesterone (24).

The sonographic appearance of thyroid nodules based on ACR-TIRADS, demonstrated the majority to be solid or almost solid, wider than tall in appearance, smooth margins, hyperechoic or isoechoic and having none or large comet-tail artifact. These findings are consistent with features often seen in normal or benign nodules. A cross-sectional study done in India among 104 patients showed similar sonographic features on the thyroid gland nodules analyzed (25). Another comparable study in the Philippines showed that the most frequent characteristics of nodules on ultrasound were solid in composition, isoechoic to hyperechoic, and wider than tall, however, few had well-circumscribed margins (26).

Of all the 161 nodules categorized based on ACR TI-RADS about $42.9 \%$ were classified as TR3, followed by TR2, only less than 10\% were TR4 and TR1, and the least common being TR5. Our findings and those from previous studies present a heterogeneous picture of ACR TI-RADS classification. For instance, a French study (27) observed a similar finding to ours, with the majority having TR3 nodules. However, a similar study from India reported TR2 as the most prevailing category (17). Regardless of these differences in the TI-RADS categorizations, the majority of the nodules in these studies were still classified as benign nodules. Our study also observed that the risk of malignancy increased as the level of ACR TI-RADS categorization increased, from $0 \%$ in TR1 and 2 to $73 \%$ and $86 \%$ in TR4 and 5 , respectively. These findings were consistently shown in studies from French (27), South Korea (10).

Our study demonstrated a significant strong positive correlation between ACR TI-RADS scoring of thyroid nodules and TBSRTC classification scores. Other studies have also found a strong correlation between the two methods (28). In addition, the study found a high sensitivity (94\%) and specificity (96\%) with excellent positive (77\%) and negative (99\%) predictive values. The ACR TI-RADS showed a positive likelihood ratio of 27 and a negative likelihood ratio of 0.06 which implies that TI-RADS is moderately good at ruling in benign or malignant thyroid nodules and at ruling out benign or malignant thyroid nodules, respectively. The ACR TI-RADS was also statistically significantly associated with FNNA results $(p<0.001)$. As compared to other studies, a study in India reveal a comparable sensitivity and specificity of over $90 \%$ (17). The study however reported a lower PPV and similar NPV (17). The low PPV in the 
Indian study is possibly due to a higher prevalence of thyroid malignancy as compared to a lower prevalence in Uganda.

This study found that hypoechogenicity on ultrasound to be a predictor of malignancy with reduced sensitivity of $54.6 \%$, but increased specificity, positive and negative predictive values of over $90 \%$. Similar studies that were done in Sri Lanka (29) and India (30) also demonstrated similar findings. Furthermore, irregular margins as well as taller than wider shapes are also predictors of malignancy albeit with low sensitivity of $31.8 \%$ while the specificity, positive and negative predictive values were almost $90 \%$. Comparable findings were reported by the same study from India (30) who observed that poorly defined irregular margins had equally low sensitivity but high specificity and positive predictive value. These findings are also similar to a study reported by Jabar et al. that showed, irregular margin and taller than wider appearance had low sensitivity and PPV and high specificity and NPV (31). On the other hand, the French study (27) showed that taller than wide as a predictor for malignancy had a very low sensitivity, good specificity, and high positive and negative predictive values.

The study had some limitations. Analysis of intra-rater variability could not be conducted since the study did not have a control group and patients could not be used as their controls due to the limited number of biopsies that can be tolerated by patients. Since patients with only ultrasound scan results were included, these introduced selection bias. The use of two biopsies from a single participant may have introduced a clustering effect which may have biased our findings.

\section{Conclusion}

We found that ACR TI-RADS is an appropriate and non-invasive method for assessing thyroid nodules in routine practice. This scoring system can safely reduce the number of unnecessary biopsies in a significant proportion of patients with benign thyroid lesions. Thyroid nodules classified as TR3 should be followed routinely. We recommend sonographic categorization of thyroid nodules using ACR TI-RADS in Uganda to create uniformity in reporting and easy guidance of appropriate biopsy.

\section{Abbreviations}

ACR

American College of Radiology

FNNA

Fine-needle none aspiration

MNRH

Mulago National Referral Hospital

NPV

Negative predictive value

PPV

Positive predictive value 
TBSRTC

The Bethesda System for Reporting Thyroid Cytopathology

TI-RADS

Thyroid Imaging Reporting and Data System

TR

TI-RADS

US

Ultrasonography

\section{Declarations}

\section{Ethics approval and consent to participate}

Written informed consent was obtained from all participants to participate in the study. Ethical approval was obtained from Makerere University School of Medicine Research and Ethics committee (REC REF 2020-200) and administrative clearance was sought from Mulago National Referral Hospital.

\section{Consent for publication}

Not applicable

\section{Availability of data and materials}

The data sets used and/or analyzed during the current study are available from the corresponding author on reasonable request.

\section{Competing interests}

The authors declare that they have no competing interests.

\section{Funding}

Self-funded

\section{Authors' contribution}

All authors made a significant contribution to the study, whether that is in the conception, study design, execution, acquisition of data, analysis, and interpretation, or in all these areas; took part in drafting, revising, or critically reviewing the article; gave final approval of the version to be published; have agreed on the journal to which the article has been submitted; and agree to be accountable for all aspects of the work.

\section{Acknowledgments}


We would like to acknowledge, the endocrine-surgery clinic staff for actively supporting the process of mobilization of study participants and data collection. We would like also to thank our statistician for his input from sample size estimation to data analysis. Special regards also to the study participants. We would like to commend, the departments of radiology and pathology for the collaborative work throughout the study period.

\section{References}

1. Dean DS, Gharib H. Epidemiology of thyroid nodules. Best Pract Res Clin Endocrinol Metab. 2008 Dec;22(6):901-11.

2. Al Dawish MA, Alwin Robert A, Thabet MA, Braham R. Thyroid Nodule Management: ThyroidStimulating Hormone, Ultrasound, and Cytological Classification System for Predicting Malignancy. Cancer Inf. 2018;17:1176935118765132.

3. Wiltshire JJ, Drake TM, Uttley L, Balasubramanian SP. Systematic Review of Trends in the Incidence Rates of Thyroid Cancer. Thyroid. 2016 Nov;26(11):1541-52.

4. Joseph-Auguste J, Lin L, Demar M, Duffas O, Molinie V, Sulpicy C, et al. Epidemiologic, Clinical, Ultrasonographic, and Cytological Features of Thyroid Nodules in Predicting Malignancy Risk: A Retrospective Study of 442 French Afro-Caribbean Patients. International Journal of Endocrinology. 2020 Mar 31;2020:e4039290.

5. Bhuiyan MMZU, Machowski A. Nodular thyroid disease and thyroid malignancy: Experience at Polokwane Mankweng Hospital Complex, Limpopo Province, South Africa. S Afr Med J. 2015 Sep 22;105(7):570-2.

6. Melak T, Mathewos B, Enawgaw B, Damtie D. Prevalence and types of thyroid malignancies among thyroid enlarged patients in Gondar, Northwest Ethiopia: a three years institution based retrospective study. BMC Cancer. 2014 Dec;2(1):899. 14(.

7. Makoba G. The role of Ultrasound and Ultrasound guided FNAB in the management of thyroid disease Kampala. Makerere University College of Health Sciences; 1999.

8. Nassanga R, Kisembo H, Othieno E, Bugeza S, Fualal J. Sonographic correlation of thyroid nodules with ultrasound aided fine needle non aspiration cytology. East Afr Med J. 2015;92(6):270-8.

9. Tessler FN, Middleton WD, Grant EG. Thyroid Imaging Reporting and Data System (TI-RADS): A User's Guide. Radiology. 2018 Mar 20;287(1):29-36.

10. Kwak JY, Han KH, Yoon JH, Moon HJ, Son EJ, Park SH, et al. Thyroid imaging reporting and data system for US features of nodules: a step in establishing better stratification of cancer risk. Radiology. 2011 Sep;260(3):892-9.

11. Tessler FN, Middleton WD, Grant EG, Hoang JK, Berland LL, Teefey SA, et al. ACR Thyroid Imaging, Reporting and Data System (TI-RADS): White Paper of the ACR TI-RADS Committee. Journal of the American College of Radiology. 2017 May 1;14(5):587-95. 
12. Azab EA, Abdelrahman AS, Ibrahim MEA. A practical trial to use Thyroid Imaging Reporting and Data System (TI-RADS) in differentiation between benign and malignant thyroid nodules. Egypt $\mathrm{J}$ Radiol Nuclear Med. 2019 Sep;6(1):17. 50(.

13. Modi L, Sun W, Shafizadeh N, Negron R, Yee-Chang M, Zhou F, et al. Does a higher American College of Radiology Thyroid Imaging Reporting and Data System (ACR TI-RADS) score forecast an increased risk of malignancy? A correlation study of ACR TI-RADS with FNA cytology in the evaluation of thyroid nodules. Cancer Cytopathol. 2020 Jul;128(7):470-81.

14. Hoang JK, Langer JE, Middleton WD, Wu CC, Hammers LW, Cronan JJ, et al. Managing incidental thyroid nodules detected on imaging: White paper of the ACR incidental thyroid findings committee. JACR Journal of the American College of Radiology. 2015 Feb 1;12(2):143-50.

15. Akushevich I, Kravchenko J, Ukraintseva S, Arbeev K, Kulminski A, Yashin Al. Morbidity risks among older adults with pre-existing age-related diseases. Exp Gerontol. 2013 Dec;48(12):1395-401.

16. Luo J, McManus $\mathrm{C}$, Chen H, Sippel RS. Are there predictors of malignancy in patients with multinodular goiter? J Surg Res. 2012 May 15;174(2):207-10.

17. Periakaruppan G, Seshadri KG, Vignesh Krishna GM, Mandava R, Sai VPM, Rajendiran S. Correlation between Ultrasound-based TIRADS and Bethesda System for Reporting Thyroid-cytopathology: 2year Experience at a Tertiary Care Center in India. Indian J Endocrinol Metab. 2018 Oct;22(5):651-5.

18. Kung AWC, Chau MT, Lao TT, Tam SCF, Low LCK. The Effect of Pregnancy on Thyroid Nodule Formation. The Journal of Clinical Endocrinology \& Metabolism. 2002 Mar 1;87(3):1010-4.

19. Knudsen N, Laurberg P, Perrild H, Bülow I, Ovesen L, Jørgensen T. Risk factors for goiter and thyroid nodules. Thyroid. 2002 Oct;12(10):879-88.

20. Pellegriti G, Frasca F, Regalbuto C, Squatrito S, Vigneri R. Worldwide increasing incidence of thyroid cancer: update on epidemiology and risk factors. J Cancer Epidemiol. 2013;2013:965212.

21. Kelly FC, Snedden WW. Prevalence and geographical distribution of endemic goitre. Bull World Health Organ. 1958;18(1-2):5-173.

22. Biswas A, Basu K, De S, Karmakar S, De D, Sengupta M, et al. Correlation between Thyroid Imaging Reporting and Data System and Bethesda System of Reporting of Thyroid Cytopathology of Thyroid Nodule: A Single Center Experience. J Cytol. 2020 Dec;37(4):193.

23. Al-Ghanimi IA, Al-Sharydah AM, Al-Mulhim S, Faisal S, Al-Abdulwahab A, Al-Aftan M, et al. Diagnostic Accuracy of Ultrasonography in Classifying Thyroid Nodules Compared with Fine-Needle Aspiration. Saudi J Med Med Sci. 2020;8(1):25-31.

24. Thattarakkal VR, Ahmed TSF, Saravanam PK, Murali S. Evaluation of Thyroid Nodule: Thyroid Imaging Reporting and Data System (TIRADS) and Clinicopathological Correlation. Indian J Otolaryngol Head Neck Surg [Internet]. 2021 Feb 23 [cited 2022 Jan 5]; Available from: https://doi.org/10.1007/s12070-021-02461-8.

25. Patil YP, Sekhon RK, Kuber RS, Patel CR. Correlation of ACR-TIRADS(thyroid imaging, reporting and data system)-2017 and cytological/ Histopathological (HPE) findings in evaluation of thyroid nodules. Int J Health Clin Res. 2020 Dec;15(11):6-19. 3(. 
26. Dy JG, Kasala R, Yao C, Ongoco R, Mojica DJ. Thyroid Imaging Reporting and Data System (TIRADS) in Stratifying Risk of Thyroid Malignancy at The Medical City. J ASEAN Fed Endocr Soc. 2017;32(2):108-16.

27. Moifo B, Takoeta EO, Tambe J, Blanc F, Fotsin JG. Reliability of Thyroid Imaging Reporting and Data System (TIRADS) Classification in Differentiating Benign from Malignant Thyroid Nodules. Open J Radiol. 2013 Sep;3(3):103-7. 3(.

28. Na DG, Baek JH, Sung JY, Kim J-H, Kim JK, Choi YJ, et al. Thyroid Imaging Reporting and Data System Risk Stratification of Thyroid Nodules: Categorization Based on Solidity and Echogenicity. Thyroid. 2016 Apr;26(4):562-72.

29. Wettasinghe MC, Rosairo S, Ratnatunga N, Wickramasinghe ND. Diagnostic accuracy of ultrasound characteristics in the identification of malignant thyroid nodules. BMC Research Notes. 2019 Apr 2;12(1):193.

30. Bhatnagar S, Mohi J, Kaur N, Kaur A, Singh. L. CORRELATION. OF TIRADS [THYROID IMAGING REPORTING AND DATA SYSTEM] AND HISTOPATHOLOGICAL FINDINGS IN EVALUATION OF THYROID NODULES. IJAR. 2017 Feb 28;5(2):1597-603.

31. Jabar ASS, Koteshwara P, Andrade J. Diagnostic reliability of the Thyroid Imaging Reporting and Data System (TI-RADS) in routine practice. Pol J Radiol. 2019 Jun 10;84:e274-80.

32. Grant EG, Tessler FN, Hoang JK, Langer JE, Beland MD, Berland LL, et al. Thyroid Ultrasound Reporting Lexicon: White Paper of the ACR Thyroid Imaging, Reporting and Data System (TIRADS) Committee. J Am Coll Radiol. 2015 Dec;12(12 Pt A):1272-9.

\section{Figures}




\section{ACR TI-RADS}

\begin{tabular}{|c|c|}
\hline \multicolumn{2}{|c|}{$\underset{\text { (Choose 1) }}{\text { COMPOSITION }}$} \\
\hline $\begin{array}{l}\text { Cystic or almost } \\
\text { completely cystic }\end{array}$ & Opoints \\
\hline Spongiform & Opoints \\
\hline $\begin{array}{l}\text { Mixed cystic } \\
\text { and solid }\end{array}$ & 1 point \\
\hline $\begin{array}{l}\text { Solid or almost } \\
\text { completely solid }\end{array}$ & 2 points \\
\hline
\end{tabular}
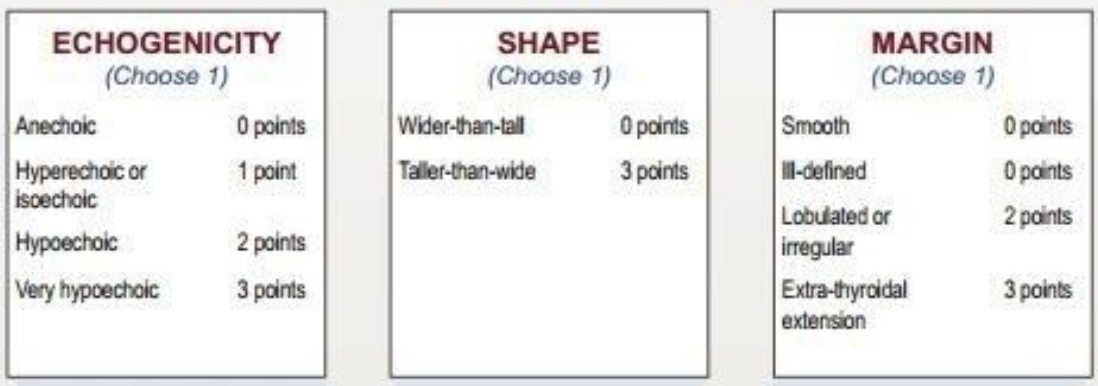

\begin{tabular}{|c|c|}
\hline $\begin{array}{l}\text { None or large } \\
\text { comet-tal artifacts }\end{array}$ & 0 points \\
\hline Macrocaldifications & 1 point \\
\hline $\begin{array}{l}\text { Peripheral (rim) } \\
\text { calcfications }\end{array}$ & 2 points \\
\hline $\begin{array}{l}\text { Punctate echogenic } \\
\text { fod }\end{array}$ & 3 points \\
\hline
\end{tabular}

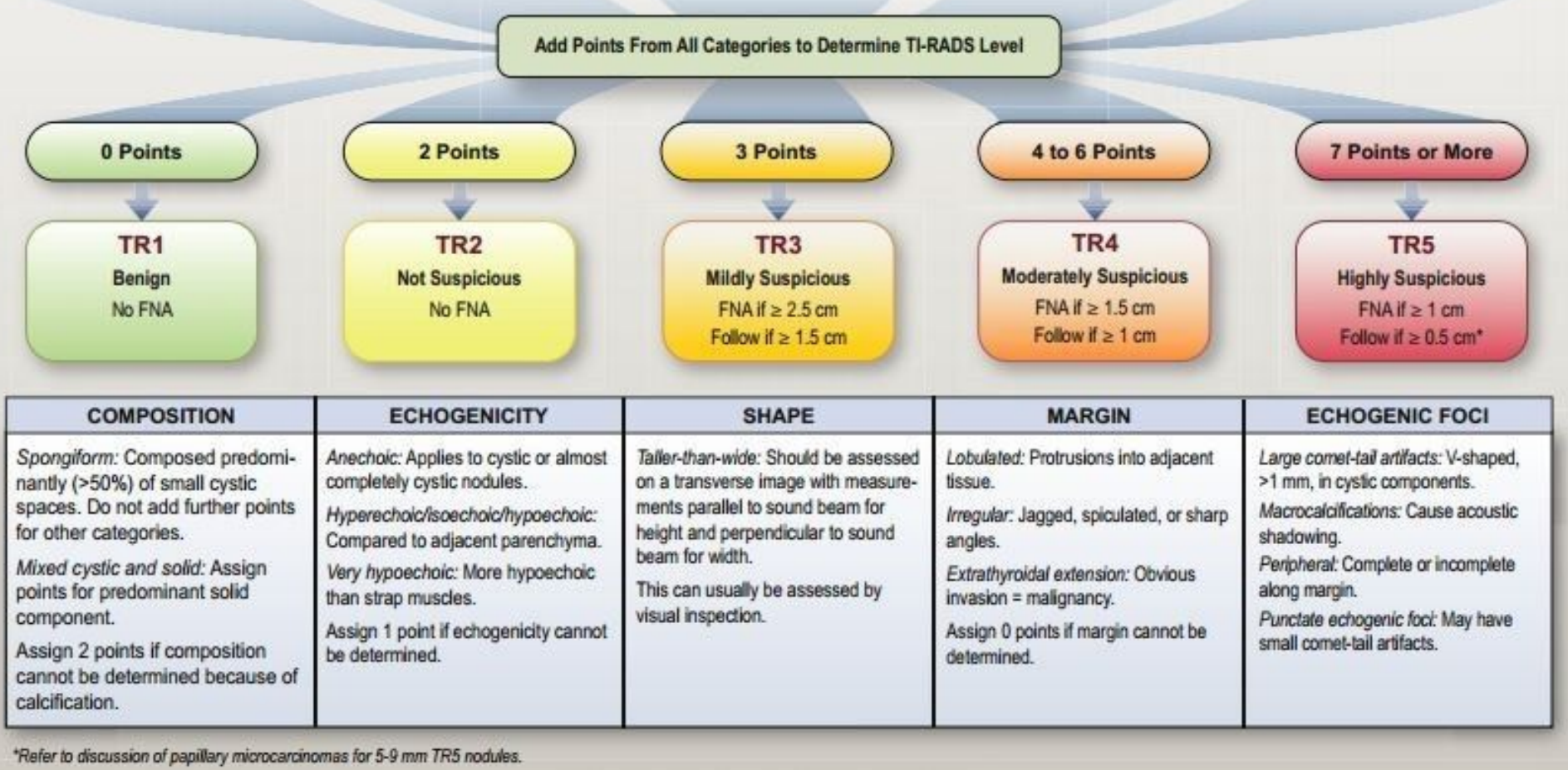

\section{Figure 1}

Nomenclature of categorization of thyroid nodules features per the five lexicon categories (32). 


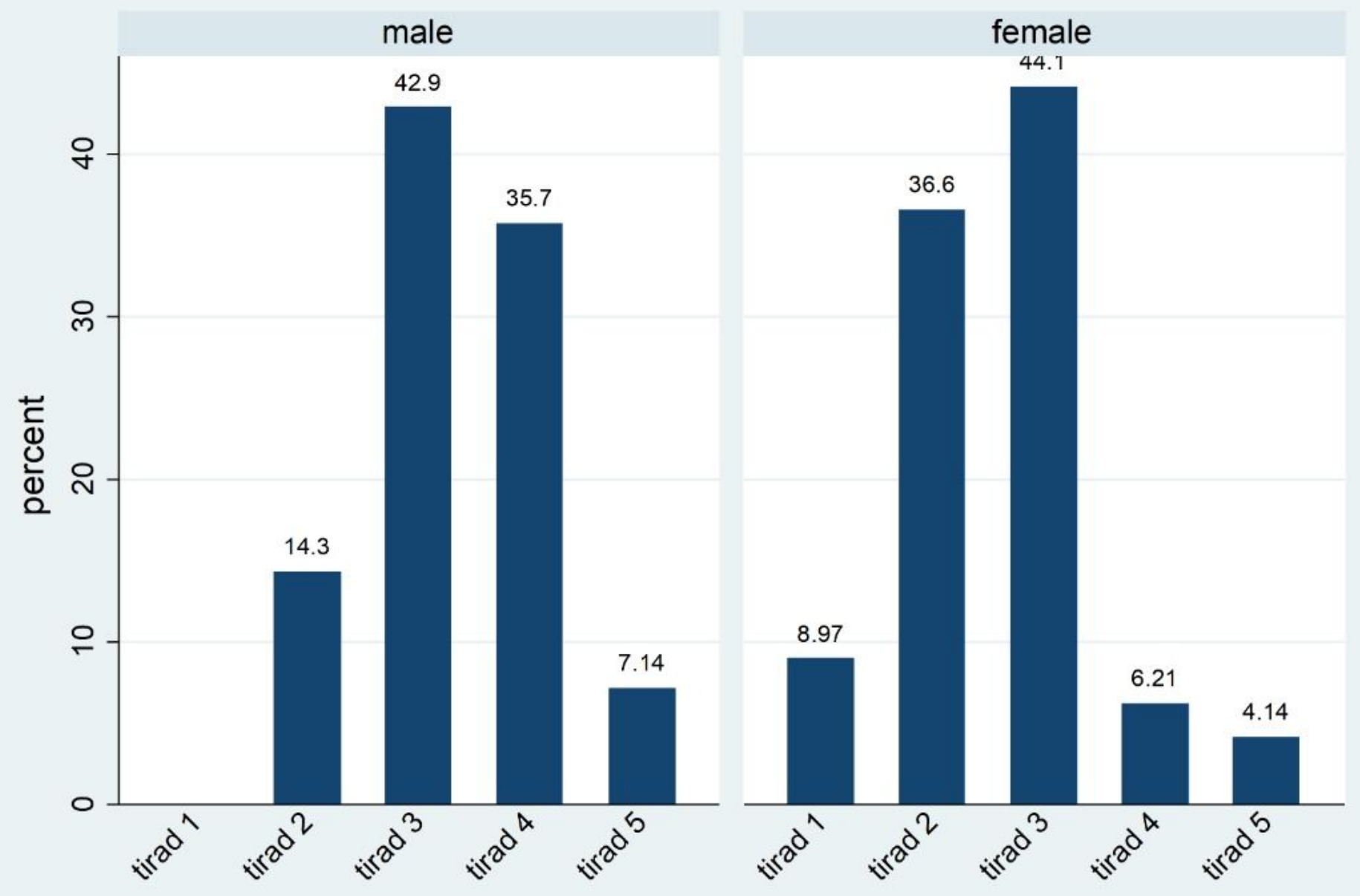

Graphs by sex of participan

Figure 2

ACR-TIRADS classification of thyroid nodules stratified by gender. 

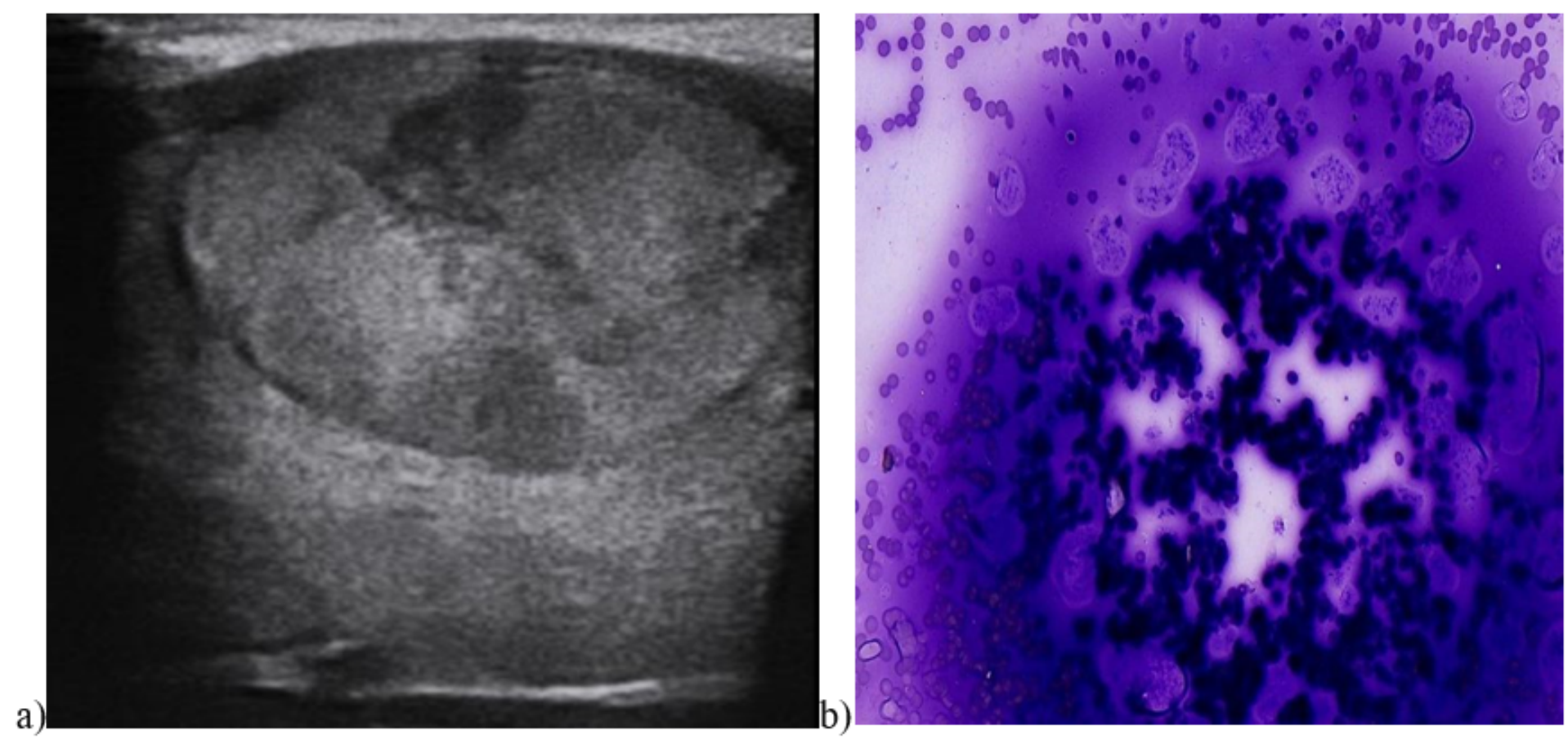

\section{Figure 3}

a) Transverse sonogram of a well-defined wider than taller isoechoic solid nodule in the upper outer quadrant of the left lobe in 24-year-old women

It was classified as solid (composition score of 2), With 1 more point for iso-echogenicity and none in other categories, its total point was 3 (TR3). Figure 17 b) Cytology result thick colloid cells (Category II Bethesda system).

A)
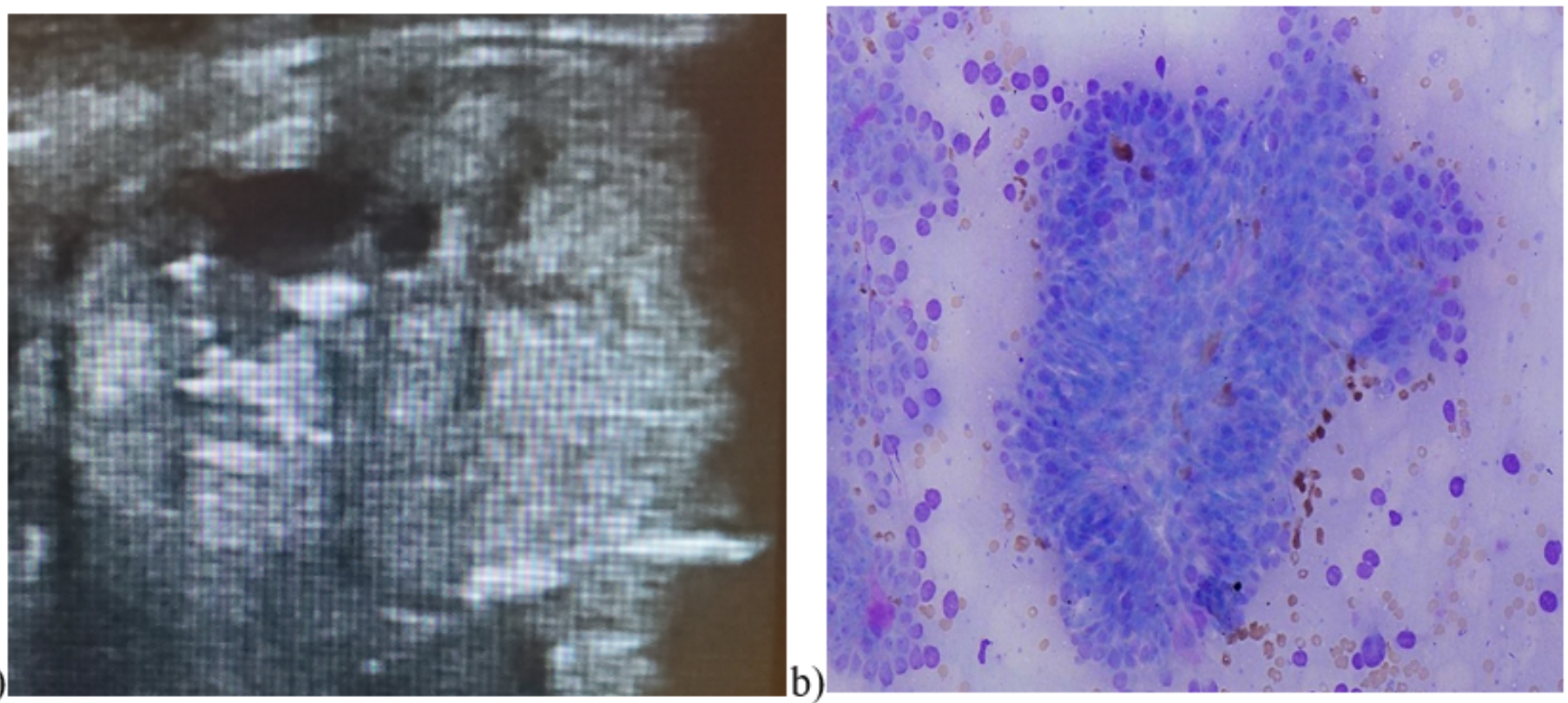


\section{Figure 4}

a) A wider than tall hyperechoic/isoechoic solid nodule with punctate calcifications in a 42-year-old man. The nodule received 2 points for solid composition, 1 for hyperechoic/isoechoic and 3 for punctate echogenic foci. Its point total was 6 (TR4).

Figure 18 b) Cytology result showed papillary thyroid carcinoma (Category VI Bethesda system). 